\title{
Effects of an Indoor Foliage Plant Intervention on Patient Well-being during a Residential Rehabilitation Program
}

\author{
Ruth Kjærsti Raanaas ${ }^{2}$ \\ Department of Plant and Environmental Sciences, Norwegian University of \\ Life Sciences, Box 5003, N-1432 As, Norway
}

Grete Grindal Patil

Department of Plant and Environmental Sciences, Norwegian University of Life Sciences, Box 5003, N-1432 As, Norway

\author{
Terry Hartig ${ }^{1}$ \\ Institute for Housing and Urban Research, Uppsala University, Box 785, \\ SE-80129 Gävle, Sweden
}

Additional index words. benefits of nature experience, healing environments, healthcare design, horticultural therapy, human issues in horticulture, people-plant interactions

\begin{abstract}
Effects of an indoor plant intervention in a Norwegian rehabilitation center were assessed in a quasi-experiment. During a 2-year period, coronary and pulmonary patients $(\mathbf{N}=\mathbf{2 8 2})$ completed self-report measures of health, subjective well-being, and emotion on arrival, after 2 weeks, and at the end of a 4-week program. The intervention involved the addition of indoor plants for the second year. On average, patient physical and mental health improved during the program, but the addition of plants did not increase the degree of improvement. Subjective well-being did, however, increase more in patients who went through their program after the addition of plants, although the effect was only apparent in the pulmonary patients. The patients reported more satisfaction with indoor plants and the interior generally after the intervention. Room for the intervention to affect outcomes may have been limited by the well-designed interior and the center's location in a scenic mountain area, but these favorable features of the context apparently did not negate the potential for indoor plants to contribute to patient well-being.
\end{abstract}

People undergoing rehabilitation must cope with a difficult life situation (Becker, 1997; Charmaz, 1997; Normann et al., 2004). The underlying health challenge may make it harder to carry out routine activities and may also arouse considerable stress, whereas the

\footnotetext{
Received for publication 6 Nov. 2009. Accepted for publication 6 Jan. 2010.

This project was financed with EXTRA funds from the Norwegian Foundation for Health and Rehabilitation. It was further supported by the Norwegian Gardener's Union, the Bank of Røros, Tropisk Design, and Primaflor.

In addition to the funders, we thank Tina Bringslimark for help in planning the study, Tropisk Design for help in implementing the plant intervention, the staff at the Røros Rehabilitation Center for their diligent assistance in conducting the study, Ellen Zakariassen for help with data entry, and the anonymous reviewers for their constructive comments.

${ }^{1}$ Terry Hartig holds a Professor II (Adjunct) position with the Departments of Plant and Environmental Sciences and Landscape Architecture and Spatial Planning at the Norwegian University of Life Sciences.

${ }^{2}$ To whom reprint requests should be addressed; e-mail ruth.raanaas@umb.no.
}

rehabilitation program itself may impose new demands. To promote rehabilitation, patients need not only the appropriate medical treatment and guidance, but also support in coping with the associated stress (Normann et al., 2004).

One widely applied approach to helping people cope with rehabilitation involves having them move temporarily to a residential rehabilitation center. The social and physical environment of the center may reduce the stress of illness and rehabilitation in several ways (Rubin et al., 1998). The patient can withdraw for a time from demands and daily routines at home and also interact with potentially supportive others who face similar health challenges (Genth, 1995). Rehabilitation centers are often located in natural surroundings, and these may offer positive distractions, tranquility, and opportunities for reflection that contrast with the usual circumstances of everyday life (Cooper Marcus and Barnes, 1999; Gerlach-Spriggs et al., 1998; Van den Berg, 2005). If well designed and furnished, the indoor environment of the center can promote feelings of comfort and aesthetic satisfaction (Ulrich, 1992).

In the present study, the focus is on the effects of indoor plants in a rehabilitation center. Our focus follows from research on the benefits of contact with nature, in healthcare contexts, and more generally. Long believed to serve therapeutic goals, contact with nature became a subject for structured empirical research and psychological theorizing only relatively recently. Studies with hospital patients have reported diverse beneficial outcomes with window views of nature (Ulrich, 1984), pictures of nature (Diette et al., 2003; Verderber, 1986), indoor plants (Park and Mattson, 2008, 2009), and other nature-related environmental stimuli (for a review, see Dijkstra et al., 2006). Experiments in simulated and actual healthcare settings have also shown an increase in pain tolerance while viewing plants (Lohr and PearsonMims, 2000; Park et al., 2004). Outside of a healthcare context, experiments with young adults have shown that viewing relatively natural environments better promotes psychophysiological recovery from acute stress than viewing built environments lacking in vegetation (e.g., Hartig et al., 2003; Parsons et al., 1998; Ulrich et al., 1991). Other experiments suggest that having indoor plants present enhances the reduction of acute stress (Dijkstra et al., 2008; Kim and Mattson, 2002; Liu et al., 2003; Lohr et al., 1996), although these findings are not entirely consistent (Bringslimark et al., 2009). Finally, a number of studies have shown that occupants of various settings, including healthcare settings, evaluate them more positively after the introduction of indoor plants (Bringslimark, 2007). The most commonly cited theoretical account for the effects listed accords a fundamental role to a biologically prepared tendency to respond positively to some natural environmental features such as vegetation (Kellert et al., 2008; Ulrich, 1983, 1992). In addition, positive symbolic values and personal associations may also contribute to beneficial effects of indoor plants (Bringslimark, 2007).

Despite the potential for informing practical applications, to our knowledge, research has not yet assessed the effects of indoor plants in a residential rehabilitation context. The present intervention study helps to fill this gap. We assessed the effect on patients of adding plants to common areas at a rehabilitation center. The outcomes of interest included self-reported health, subjective well-being, emotions, and satisfaction with the interior environment at the center.

\section{Materials and Methods}

Design and participants. A quasiexperimental assessment was conducted at the Røros Rehabilitation Center in Norway. It involved a nonequivalent control group design with repeated measures, which enabled comparison of change in participants in rehabilitation during a pre-intervention period (the control group) with change in participants in rehabilitation during a comparable period after the intervention (the intervention group).

The Røros Rehabilitation Center offers rehabilitation programs for different diagnostic 
groups. One group consists of people who have undergone heart surgery and people with a history of coronary heart disease, including cardiac infarction and angina pectoris (here, "heart" patients). Another diagnostic group consists mainly of people with asthmatic diseases or chronic obstructive pulmonary disease (here, "lung" patients). Our sample included both heart and lung patients.

Large differences in light and temperature between the summer and winter seasons in Norway mean that the outdoor environment at the center varies over the year in terms of comfortable accessibility for people with heart and lung conditions. For this reason, the importance of the indoor environment of the center may also vary across the seasons. We therefore sampled patients across comparable periods of the year before the intervention (Jan. to Nov. 2007) and after the intervention (Jan. to Nov. 2008).

Patients at the center normally stay for a fixed 4-week program. The programs for the heart and lung patients are run with groups of, at most, 20 participants. In a few cases, during the period of the study, a participant interrupted his or her stay for health-related or personal reasons. The study included only participants who stayed for at least 3 of the 4 weeks of a program run during the period of data collection. Data were collected from patients in 8 lung and 10 heart groups in 2007, before the intervention (control group), and 8 lung and 10 heart groups in 2008, after the intervention (intervention group).

The participants received a set of questionnaires at five different time points: 2 weeks before arrival at the rehabilitation center (T0), at the time of arrival (T1), 2 weeks after arrival (T2), at the end of the 4week program (T3), and 2 weeks after returning home (T4). For the present purposes, we focused on change in outcomes only during the period that the patients were at the center (T1 to T3); however, we used T0 data for statistical control purposes.

In all, 595 people participated in one of the center's heart or lung programs during the period for data collection (345 heart and 250 lung patients). Of them, 436 (73.3\%) participated in the study by completing at least one set of questionnaires at the center (T1 to T3). Among the 436 respondents, 282 (64.7\%) completed all three sets of questionnaires distributed at the rehabilitation center and were included in the analysis. Of these respondents, $28(9.9 \%)$ did not have complete data from T0. Altogether, 80 heart and 64 lung patients participated in 2007, and 88 heart and 50 lung patients participated in 2008. The control group included 50 women and 94 men, and the intervention group included 41 women and 97 men. Mean age in the control group was 63.1 years (SD, 9.04 years; range, 35 to 86 years) and in the intervention group 62.4 years (SD, 8.42 years; range, 37 to 81 years).

The study was approved by the Regional Committee for Medical and Health Research Ethics and the Norwegian Social Science
Data Service. The participants signed an informed consent form before participation in the study.

Research context. The Norwegian National Association for Heart and Lung Disease had a rehabilitation center built in 2003 just outside the mountain village of Røros, which is a UNESCO World Heritage site. The center's architecture is modern with large open spaces, large windows, light colors, and natural elements like wood and stone used extensively in the interior. The three-level building follows the contours of the landscape. Window views from the bedrooms encompass the valley and the mountains, although some are blocked by sections of the building itself or neighboring houses. Window views from the common areas are, in contrast, generally less extensive with some dominated by grass and low vegetation around the center and others facing onto the building itself, parking areas, or other buildings.

Each group of 20 patients at the center is taken care of by a team of staff members representing different professions (physical therapy, occupational therapy, nutrition, bioengineering, nursing, medicine). All patients participate in a demanding program with different types of physical training, education in lifestyle change, and meetings to enhance social support. The team of staff members remained essentially the same for every one of the heart and lung groups that participated in the study. Thus, the groups of patients would have had a similar experience in important respects looking across the 2 years of the intervention.

Intervention. The rehabilitation center had few interior plants at the beginning of the study, and these were not well maintained. Plants had been kept out of the bedrooms as a result of concerns about allergic reactions by patients. For the intervention, 28 additional pots of plants were placed in the common areas in Nov. 2007, just after data collection for the control group was completed. Data collection for the intervention group did not start until Jan. 2008 so that the staff members had time to get used to the plants and so that data would be collected during the same period of the year as with the control group.

The tropical and nontropical foliage potted plants selected for the intervention are known to adapt to low to moderate indoor light levels, tolerate low air humidity, have a low potential for causing allergic reactions, and be easy to maintain. They were planted in self-watering anthracite (dark gray)-colored containers of two types, 'Lechuza Classico' (Brandstaetter GmbH \& Co., Zirndorf, Germany) and 'Hydrocultur bakken' (Nieuwkoop, De Kwakel, The Netherlands). They were placed in the reception area, the four TV rooms, and close to sitting areas in the corridor (Fig. 1). Each of these areas is frequently visited and/or passed in the course of an ordinary day at the center. No plants were placed in the bedrooms (Table 1).

Aside from the introduction of plants for the intervention and removal of some old plants, no other changes were made to the interior decoration during the study period. A staff member took care of the plant maintenance during the intervention, and a member of the research team trained in horticulture (Grete Grindal Patil) made periodic checks on the health of the plants.

Procedure. Data collection took place from Jan. to Nov. 2007 and from Jan. to Nov. 2008. A secretary at the rehabilitation center was responsible for mailing out the first (T0) and last (T4) questionnaires. She also maintained the coding key with participants' names and registration codes, ensuring their

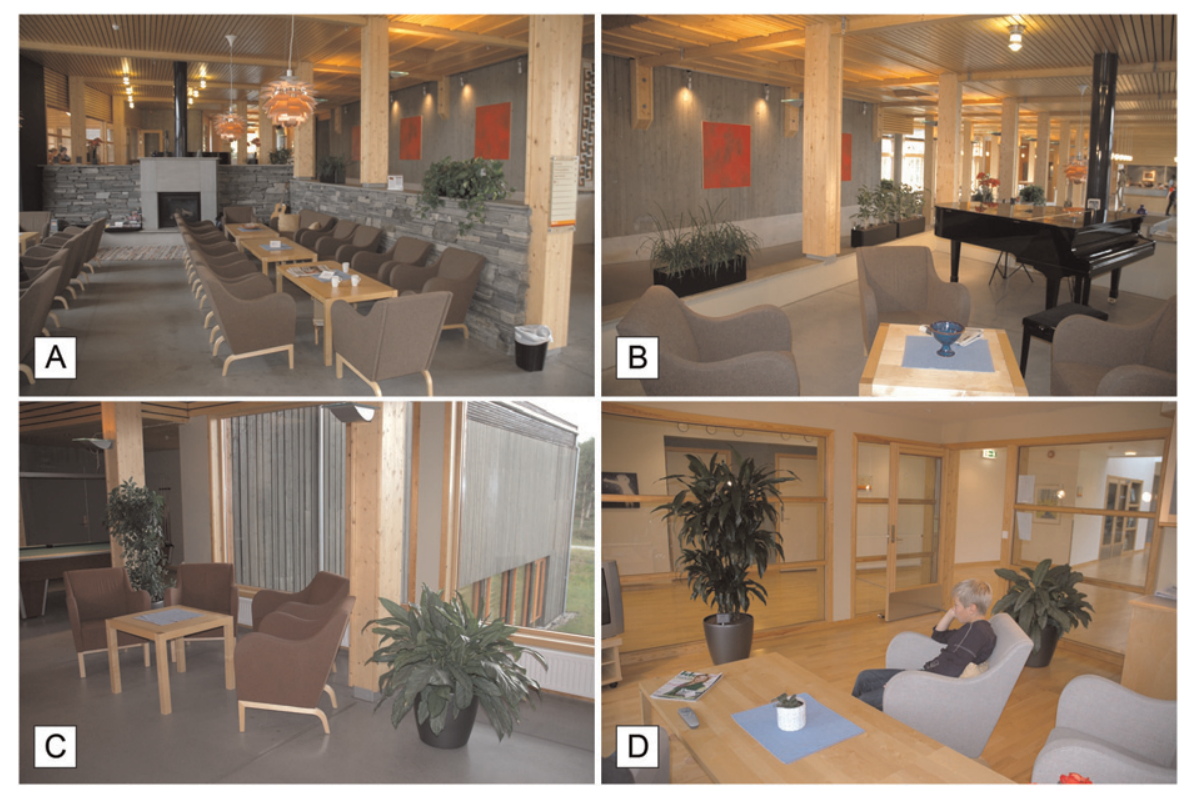

Fig. 1. Photographs that illustrate the plant intervention in the reception area from two different viewpoints (A) and (B), a sitting area in the corridor $(\mathbf{C})$, and a TV room (D). 
Table 1. Description and spatial distribution of the potted plants used in the intervention.

\begin{tabular}{|c|c|c|c|c|c|}
\hline Location & Plant species & Plant ht & $\begin{array}{l}\text { No. of } \\
\text { plants } \\
\text { per pot }\end{array}$ & $\begin{array}{c}\text { Number } \\
\text { of pots }\end{array}$ & $\begin{array}{l}\text { Pot } \\
\text { type }\end{array}$ \\
\hline \multirow[t]{6}{*}{ Reception area } & Dracaena reflexa 'Song of Jamaica' & $130 \mathrm{~cm}$ & 1 & 1 & $\mathrm{LC}^{\mathrm{z}}$ \\
\hline & Rhapis excelsa & $180 \mathrm{~cm}$ & 1 & 2 & $\mathrm{LC}$ \\
\hline & Schefflera arboricola & $50 \mathrm{~cm}$ & 1 & 1 & $\mathrm{LC}$ \\
\hline & Dracaena surculosa & $30 \mathrm{~cm}$ & 4 & 2 & $\mathrm{HB}^{\mathrm{y}}$ \\
\hline & Epipremnum aureum & Basket type & 4 & 4 & $\mathrm{HB}$ \\
\hline & Liriope muscari & $25 \mathrm{~cm}$ & 4 & 2 & $\mathrm{HB}$ \\
\hline \multirow[t]{4}{*}{ Corridors } & Schefflera arboricola & $160 \mathrm{~cm}$ & 1 & 2 & $\mathrm{LC}$ \\
\hline & & $50 \mathrm{~cm}$ & 1 & 2 & $\mathrm{LC}$ \\
\hline & Aglaonema commutatum & $60 \mathrm{~cm}$ & 3 & 2 & $\mathrm{LC}$ \\
\hline & Dracaena reflexa 'Song of Jamaica' & $130 \mathrm{~cm}$ & 1 & 1 & $\mathrm{LC}$ \\
\hline \multirow[t]{3}{*}{ TV room $32.1 \mathrm{~m}^{2}$} & Dracaena fragrans 'Janet Craig' & $150 \mathrm{~cm}$ & 1 & 1 & $\mathrm{LC}$ \\
\hline & Aglaonema commutatum & $60 \mathrm{~cm}$ & 3 & 1 & $\mathrm{LC}$ \\
\hline & Schefflera arboricola & $50 \mathrm{~cm}$ & 1 & 1 & $\mathrm{LC}$ \\
\hline
\end{tabular}

${ }^{\mathrm{z}} \mathrm{LC}=$ Lechuza Classico (diameter $\times$ height: $43 \times 40 \mathrm{~cm}$ for all plants, except for Rhapis excelsa where $50 \times$ $47 \mathrm{~cm}$ were used).

${ }^{\mathrm{y}} \mathrm{HB}=$ Hydrocultur bakken $(80 \mathrm{~cm}$ long $\times 20 \mathrm{~cm}$ wide $\times 23 \mathrm{~cm}$ high $)$.

anonymity. An invitation letter explaining the purpose of the study was attached to the first questionnaire (T0). The participants returned the first and last identity-coded questionnaires (T0 and T4) to the researchers with preaddressed, postage-paid return envelopes. A member of the staff team working with each lung or heart group handed out the questionnaires for T1, T2, and T3 with instructions to fill them out and return them quickly in a mailbox placed in the center's reception area. The secretary and staff members were instructed to not relate the questionnaires to the plants or in other ways discuss the objectives of the study with the participants. No attempts were made to follow-up on participants who did not complete one or more of the questionnaires.

Measures. The present study was part of a larger project, and some of the questions presented to the participants were not relevant to this study's purposes. Data relevant for this study concerned health, subjective well-being, emotional states, and environmental evaluations.

The SF-12 (Ware et al., 2005) measures physical and mental health. It is the short version of the SF-36 (Ware et al., 1996); it consists of 12 rather than 36 questions. Both the SF-12 and the SF-36 have been widely used to measure of physical and mental health among different clinical and normal populations. The SF-12 includes questions about self-perceived health; the degree to which poor health limits daily physical activities (e.g., climbing several flights of stairs, pushing a vacuum cleaner); the degree to which, during the preceding week, poor physical health limited work performance or other daily activities; the degree to which, during the preceding week, poor mental health limited work or other daily activities; the degree to which, during the preceding week, pain limited paid and unpaid (domestic) work; the amount of time during the last week spent feeling calm and peaceful, energetic, and downhearted and blue; and the amount of time during the last week that physical health or emotional problems interfered with social activities. Different items had different response formats, and scores for the physical and mental health dimensions of the SF-12 were calculated following the instructions provided in the SF-12 Version 2 manual (Ware et al., 2005). Scores could range from 0 to 100 for both measures with lower scores indicating poorer health. The SF-12 was administered at all of the time points relevant for the present study (T0 to T4).

Subjective well-being was measured at T0 through T4 with a single item ("When you look at your life in general, how happy would you say that you are?") (e.g., AbdelKhalek, 2006). Responses were given using an 11-point scale $(0=$ extremely unhappy, $10=$ extremely happy).

Measures of momentary emotional wellbeing were obtained at $\mathrm{T} 0$ through $\mathrm{T} 4$ using items from a scale based on the circumplex model of affect (Russell, 1979; Russell and Mehrabian, 1977). The model organizes affective states around a circumplex centered on the midpoints of two orthogonal dimensions, activation and pleasantness. It thus represents all affective states as describable in terms of the amount of activation and pleasantness they involve. We focused on the affects within the activated-unpleasant (AUP) and unactivated-pleasant (UAP) octants of the circumplex. Four adjectives (annoyed, fearful, jittery, and anxious) were used to measure AUP affect, and four others (relaxed, content, at rest, and calm) were used to measure UAP affect. Working from the original scale by Russell (1979), Knez and Hygge (2001) developed a Swedish version of the affect circumplex measure that provided an intermediate step to the selection of Norwegian adjectives for the present measure. Participants reported how much of the given emotion they were feeling at that moment using a 5 -point scale $(1=$ not at all; 5 = very much). The mean item response was calculated for AUP and UAP. The two measures, UAP and AUP, were collapsed for the analyses presented here, because analysis of the individual measures showed that they mirrored one another. Internal consistency (Cronbach's alpha) ranged from 0.83 to 0.87 across the three time points for the eight activated unpleasant/unactivated pleasant emotion items.

Negative affectivity (Denollet, 2005) was measured at $\mathrm{T} 0$ to be used as a covariate in the analyses. Responses to seven items (e.g., I often feel unhappy; I am often irritated; I take a gloomy view of things) were given with 5point scales ( $1=$ not true; $5=$ absolutely true $)$. A mean item score was calculated based on the seven items. The measure was internally consistent $($ Cronbach's alpha $=0.87$ ).

The environmental evaluations consisted of two sets of questions. One set included a question about the degree of satisfaction with the plants in the common areas $(0=$ not at all; $4=$ very much) and the appropriateness of the amount of plants in the common areas $(0=$ too little; $1=$ appropriate; $2=$ too much $)$. Responses to the latter question were recoded before calculation of a mean score $(1=$ too little or too much; 3 = appropriate). Scores for the satisfaction with plants measure thus could range from 0.5 (not at all satisfied with the plants) to 3.5 (very much satisfied with the plants).

The second set of environmental evaluations included questions about the degree of satisfaction with the interior generally and with the decoration in the common areas $(0=$ not at all; $4=$ very much) and a question about the appropriateness of the amount of decoration $(0=$ too little; $1=$ appropriate $;=$ too much). Responses to the latter question were recoded $(1=$ too little or too much; $3=$ appropriate) before calculation of a mean score. Scores for the satisfaction with the interior measure thus could range from 0.33 (not at all satisfied with the interior) to 3.67 (very much satisfied with the interior).

A variety of sociodemographic variables were measured at T0. Those used in the present study included gender, age, education (four levels: primary/secondary school, technical school, high school, university) and the household total income level (six levels presented in 1000s of NOK: under 100, 100 to 199,200 to 299,300 to 399,400 to 499 , above 500).

Statistical analyses. Imputations for missing data were made at the item level using the expectation maximization method (Tabachnick and Fidell, 2007) with data for other items from the same questionnaire at the same time point used for reference. Repeated-measures analyses of variance (RM-ANOVA) were used to assess the effects of the intervention on change in the self-reported health, subjective well-being, and emotion outcomes across the three time points that patients were at the center. For all of these analyses, gender and patient group were treated as between-subject factors along with membership in the control versus treatment group. For the analyses of change in the health, wellbeing, and emotion outcomes, the corresponding measures from $\mathrm{T} 0$, age, and negative affectivity were used as covariates. ANOVA was also used to assess intervention effects on satisfaction with the interior and with plants in the common areas. These 
analyses also used gender and patient group as between-subject factors and age and negative affectivity as covariates.

Education, income, and season of the year were also considered as potential explanatory variables. Season was coded into two categories: winter, or the darker half of the year, included those participants who entered the center during Weeks 1-10 and 39-42, whereas summer, or the lighter half of the year, included those participants who entered the center during Weeks 11-38. This coding reflects a distinction commonly made in Scandinavia between the winter half-year and the summer half-year. Bivariate analyses confirmed that the intervention and control groups had similar numbers of participants distributed across the categories for education $\left(\chi^{2}=4.13, P=0.248\right)$, income $\left(\chi^{2}=1.81\right.$, $P=0.875)$, and season $\left(\chi^{2}=2.721, P=\right.$ 0.099). When included in initial RMANOVA as between-subject factors, none of these variables modified the effect of the intervention (i.e., the amount of change in the intervention group relative to the control group was not dependent on education, income, or season). To simplify the presentation, we therefore excluded season, education, and income level from the analyses reported here.

\section{Results}

Before entering the rehabilitation center (T0), the patients generally had relatively low SF-12 scores for physical health (mean, 39.87) and mental health (mean, 38.70) compared with those obtained for a sample from the Norwegian general population aged 45 to 65 years $(\mathrm{N}=565)$ (48.6 for physical health, 51.4 for mental health) and aged 65 to 74 $(\mathrm{N}=176$ ) (43.3 for physical health, 53.1 for mental health) (Gandek et al., 1998). The scores for the present sample were also low relative to norms for the American general population that are widely used internationally (49.63 for physical health, 49.37 for mental health) (Ware et al., 2005).

Self-reported physical and mental health improved over the time spent at the center (Fig. 2). Although the change in self-reported health during the time at the center is of itself statistically significant, it was not greater among the patients who received the plant intervention. The health of the plant and the no-plant groups improved to a similar degree as indicated by the nonsignificant time $\times$ plant interaction reported in Table 2 . This held true regardless of gender and patient group.

Subjective well-being also improved over the time spent at the center. The degree of change in subjective well-being during the rehabilitation program was sensitive to both the plant intervention and patient group (Fig. 3 ). Lung patients in the plant group reported larger improvement during the course of the program than the lung patients in the control condition, whereas this was not the case for the heart patients. The three-way interaction of time, plant intervention, and patient group

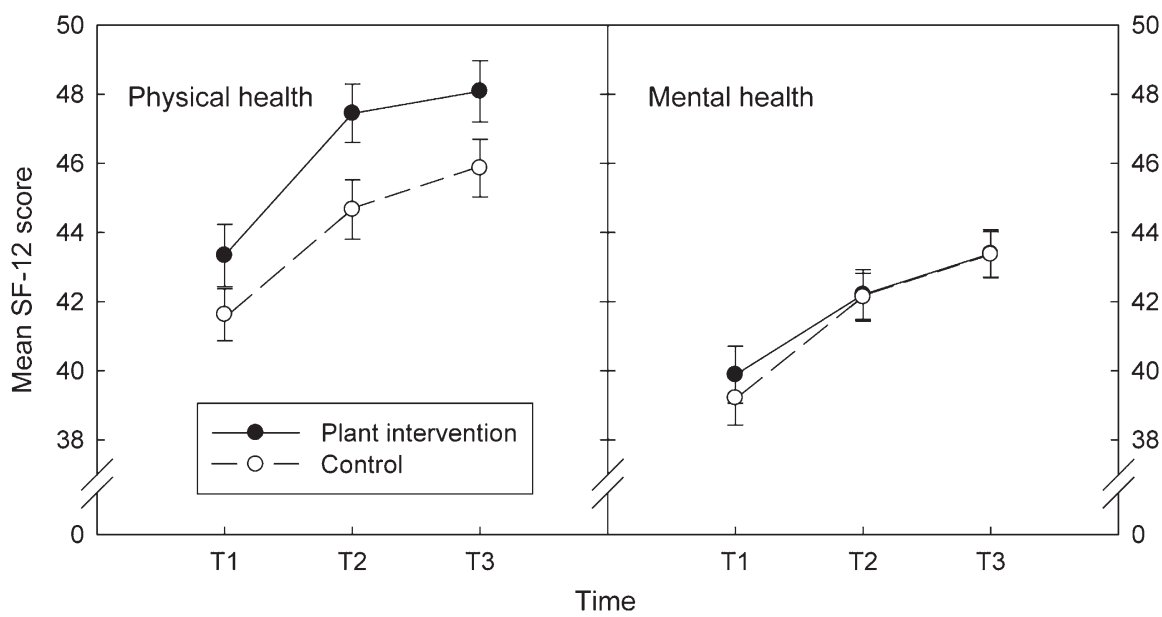

Fig. 2. Change in self-reported physical and mental health during the rehabilitation program as a function of the plant intervention. As measured with the SF-12 instrument, the scale for both outcomes ranges from 0 to 100 with lower scores indicating poorer health. Error bars show \pm one SE.

Table 2. Effects on self-reported health, subjective well-being, and activated unpleasant/unactivated pleasant emotions of time at the center per se and as moderated by the plant intervention, gender, and patient group.

\begin{tabular}{|c|c|c|c|c|}
\hline & & $\mathrm{F}(2,542)$ & $P$ & Partial eta ${ }^{2}$ \\
\hline \multirow[t]{4}{*}{ SF-12 Physical } & Time & 7.76 & $<0.001$ & 0.028 \\
\hline & Time $\times$ plants & 1.31 & 0.271 & 0.005 \\
\hline & Time $\times$ plants $\times$ gender & 0.95 & 0.389 & 0.003 \\
\hline & Time $\times$ plants $\times$ group & 0.02 & 0.978 & $<0.001$ \\
\hline \multirow[t]{4}{*}{ SF-12 Mental } & Time & 3.38 & 0.035 & 0.012 \\
\hline & Time $\times$ plants & $<0.01$ & 0.998 & $<0.001$ \\
\hline & Time $\times$ plants $\times$ gender & 0.55 & 0.580 & 0.002 \\
\hline & Time $\times$ plants $\times$ group & 0.11 & 0.893 & $<0.001$ \\
\hline \multirow[t]{4}{*}{ Well-being } & Time & 6.50 & 0.002 & 0.023 \\
\hline & Time $\times$ plants & 1.17 & 0.312 & 0.004 \\
\hline & Time $\times$ plants $\times$ gender & 0.17 & 0.844 & 0.001 \\
\hline & Time $\times$ plants $\times$ group & 4.17 & 0.016 & 0.015 \\
\hline \multirow[t]{4}{*}{ Emotions } & Time & 1.35 & 0.260 & 0.005 \\
\hline & Time $\times$ plants & 3.43 & 0.033 & 0.012 \\
\hline & Time $\times$ plants $\times$ gender & 0.28 & 0.754 & 0.001 \\
\hline & Time $\times$ plants $\times$ group & 1.18 & 0.309 & 0.004 \\
\hline
\end{tabular}

was statistically significant (Table 2). This held even with adjustment for variation among scores measured at T0.

Emotional states also appear to have improved over the course of the rehabilitation program. The pattern of change was contingent on the plant intervention with the control group showing relatively more improvement in the initial weeks and the plant group showing relatively more improvement in the final weeks (Fig. 4). This pattern accounts for the significant time $\times$ plant interaction (Table 2).

The average levels of satisfaction with the plants and the interior as a function of plant and gender are shown in Figure 5. Those patients who were at the center during the plant intervention were significantly more satisfied with the indoor plants (mean, 3.06 versus 2.58) and with the interior generally (mean, 3.25 versus 3.19) (Table 3). Women expressed more satisfaction with the presence of the plants than the men did, and they were also more satisfied with the interior generally after the plants were installed. These interactions between gender and plant intervention were significant (Table 3). The three-way interaction between plant, gender, and patient group was not significant for either of the two satisfaction measures.

\section{Discussion}

The present study addressed the question of whether the addition of indoor plants in the common areas in a rehabilitation center would improve self-reported physical and mental health, subjective well-being, and emotions among patients over the course of a rehabilitation program. It also considered whether the addition of plants would improve satisfaction with the interior of the center.

We found no significant direct effects of the plant intervention on change in either of the self-reported health outcomes. The results do, however, indicate that the plant intervention affected the degree of change in subjective well-being, although this effect was further contingent on patient group. That is, subjective well-being increased more during the rehabilitation program in the plant versus the no-plant control group, although only among the lung patients. This result was obtained with statistical control for the initial 
(T0) variation in scores as well as for age and negative affectivity. That said, the effect size for the interaction is quite small as are the effect sizes in general, including those for time at the center per se.

Although the plants were introduced in relatively modest amounts to the common areas and were a minor part of the interior in general, the plant intervention had a positive effect on satisfaction with the interior of the rehabilitation center as well as satisfaction with plants in the common areas. This is in line with the notion that nature and natural elements are highly preferred (Kaplan and Kaplan, 1989; Ulrich, 1983) and judged to have psychological restorative effects in a variety of settings (e.g., Nordh et al., 2009).

That the evaluation of the plants changed with the addition of plants is not surprising; there were only a few poorly maintained exemplars before the intervention. It is more interesting that the evaluation of the interior as a whole proved sensitive to the presence of more plants. However, just how the plants affected the assessment of the interior cannot

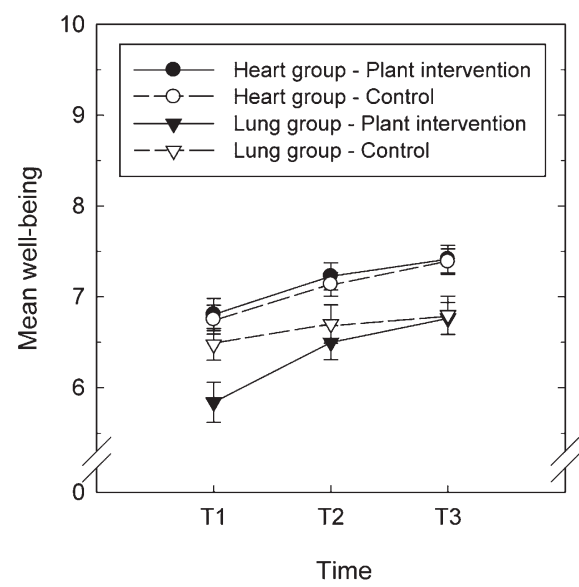

Fig. 3. Change in subjective well-being during the rehabilitation program as a function of plant intervention and patient group. The scale ranges from 0 (extremely unhappy) to 10 (extremely happy). Error bars show \pm one SE.

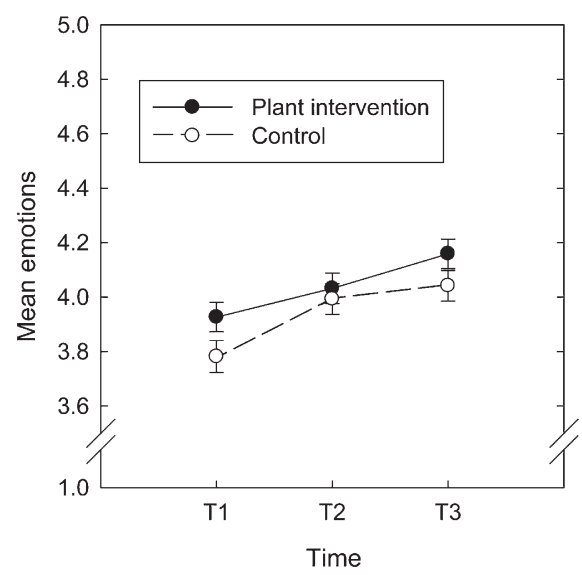

Fig. 4. Change in emotions during the rehabilitation program as a function of plant intervention. The scale ranges from 1 (not at all) to 5 (very much). Error bars show \pm one SE. be answered by the present study. We do not know, for example, whether the plants gave the impression of a more "home-like" atmosphere or whether they were simply pleasant objects to look at, or something else entirely. Conceivably, the differences between the plant and the no-plant group found in the present study may have been caused by a factor other than the presence of the plants. The introduction of the plants may, for example, have affected the staff members' behavior, which in turn may have influenced the participants. We did, however, anticipate this possibility, and so allowed a substantial amount of time ( $\approx 2$ months) to pass between installation of the plants and the collection of data from patients in the intervention group. Given the quasi-experimental design, it is also possible that differences found between the intervention and control group in the outcomes of interest had to do with pre-existing differences between the groups rather than the actual intervention. However, in that we used T0 values as statistical controls and looked at specific differences in patterns of change in outcomes, we can have more confidence in the effects uncovered.

One reason why the plant intervention did not influence the health outcomes in the present study may be that the participants were mobile and were exposed to a variety of treatments and activities at the center. This contrasts with the case in, for example, Park and Mattson's $(2008,2009)$ studies, in which plants seemed to engender better pain management among patients who it appears stayed mainly in a single hospital room. It should also be emphasized that the center and

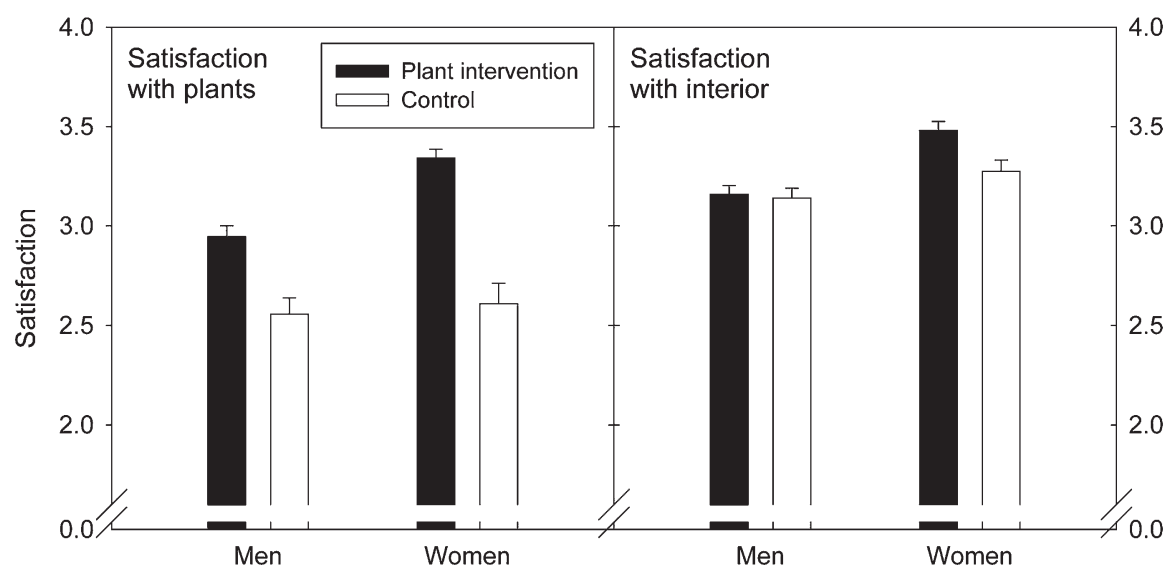

Fig. 5. The mean scores for satisfaction with indoor plants and the interior of the rehabilitation center as a function of the presence of the plants and gender. The respective scales range from 0.50 (not at all satisfied with the plants) to 3.50 (very much satisfied with the plants) and from 0.33 (not at all satisfied with the interior) to 3.67 (very much satisfied with the interior). Error bars show \pm one SE.

Table 3. Effects on plant satisfaction and satisfaction with the interior of the plant intervention per se and as moderated by gender and patient group.

\begin{tabular}{llccc}
\hline & & $\mathrm{F}(1,272)$ & $P$ & Partial eta $^{2}$ \\
\hline Satisfaction plants & Plants & 50.88 & $<0.001$ & 0.158 \\
& Plants $\times$ gender & 6.77 & 0.010 & 0.024 \\
& Plants $\times$ group & 1.06 & 0.305 & 0.004 \\
Satisfaction interior & Plants & 3.80 & 0.052 & 0.014 \\
& Plants $\times$ gender & 5.22 & 0.023 & 0.019 \\
& Plants $\times$ group & 1.54 & 0.216 & 0.006 \\
\hline
\end{tabular}

the environment at Røros include a variety of options for restoration from stress and that the plant intervention is relatively modest, representing only a moderate change to the spacious common areas. Kellert (2005) maintains that other natural elements in the interior design such as wood and stone may also trigger beneficial, "biophilic" responses. These as well as window views to nature might have further washed out possibilities for detecting prospective plant effects (Bringslimark, 2007). Had the patients been environmental intervention involved larger amounts of plants, and the overall environment afforded less contact with nature, then the plant effects might well have been

The results in the present study are based on data from those patients who completed all three questionnaires administered during the time spent at the center $(64.7 \%$ of the total of responders). These patients might not be representative of all patients who undergo the rehabilitation program there. that they did not receive the questionnaires at $\mathrm{T} 2$ and $\mathrm{T} 3$ as a result of problems with staff routines during vacation periods. This explathe pation not related to the health ing may, however, be so those with worse health may have had less energy for extra activities over and above those in the already relatively healthy patients may have found time for filling in the questionnaires. In the spond to all three sets of questionnaires was rather full program schedule, so only the 
case that those in worse health would have received more benefit from the intervention, this pattern of nonresponse would bias downward the effect estimates.

For a rehabilitation process to be successful, it should help to provide patients not only with the appropriate treatment, but also with a supportive environment. Although the interior design might be regarded as a relatively minor environmental factor, and the indoor plants a relatively minor part of the interior, our findings suggest that as positively evaluated features of the environment, they may nonetheless contribute positively to patient well-being.

\section{Literature Cited}

Abdel-Khalek, A.M. 2006. Measuring happiness with a single-item scale. Soc. Behav. Pers. 34:139-149.

Becker, G. 1997. Disrupted lives: How people create meaning in a chaotic world. Univ. of California Press, Berkeley, CA.

Bringslimark, T. 2007. Psychological benefits of nature in the indoor context. $\mathrm{PhD}$ thesis Norwegian University of Life Sciences, Aas, Norway.

Bringslimark, T., T. Hartig, and G.G. Patil. 2009. The psychological benefits of indoor plants: A critical review of the experimental literature. J. Environ. Psychol. 29:422-433.

Charmaz, K. 1997. Identity dilemmas of chronically ill men. In: Strauss, A. and J. Carbin (eds.). Grounded theory in practice. Sage Publications, Thousand Oaks, CA.

Cooper Marcus, C. and M. Barnes. 1999. Healing gardens: Therapeutic benefits and design recommendations. Wiley, New York, NY.

Denollet, J. 2005. DS14: Standard assessment of negative affectivity, social inhibition, and Type D personality. Psychosom. Med. 67:89-97.

Diette, G.B., N. Lechtzin, E. Haponik, A. Devrotes, and H.R. Rubin. 2003. Distraction therapy with nature sights and sounds reduces pain during flexible bronchoscopy: A complementary approach to routine analgesia. Chest 123:941948.

Dijkstra, K., M. Pieterse, and A. Pruyn. 2006. Physical environmental stimuli that turn healthcare facilities into healing environments through psychologically mediated effects: Systematic review. J. Adv. Nurs. 56:166-181.

Dijkstra, K., M.E. Pieterse, and A. Pruyn. 2008. Stress-reducing effects of indoor plants in the built healthcare environment: The mediating role of perceived attractiveness. Prev. Med. 47:279-283.

Gandek, B., J.E. Ware, N.K. Aaronson, G. Apolone, J.B. Bjorner, J.E. Brazier, M. Bullinger, S. Kaasa, A. Leplege, L. Prieto, and M. Sullivan. 1998. Cross-validation of item selection and scoring for the SF-12 Health Survey in nine countries: Results from the IQOLA Project. J. Clin. Epidemiol. 51:1171-1178.

Genth, E. 1995. Current and future role and objectives of clinics for rehabilitation. $\mathrm{Z}$. Rheumatol. 54:202-206.

Gerlach-Spriggs, N., R.E. Kaufman, and S.B. Warner, Jr. 1998. Restorative gardens: The healing landscape. Yale Univ. Press, New Haven, CT.

Hartig, T., G.W. Evans, L.D. Jamner, D.S. Davis, and T. Gärling. 2003. Tracking restoration in natural and urban field settings. J. Environ. Psychol. 23:109-123.

Kaplan, R. and S. Kaplan. 1989. The experience of nature: A psychological perspective. Cambridge Univ. Press, Cambridge, UK.

Kellert, S.R. 2005. Building for life: Designing and understanding the human-nature connection. Island Press, Washington, DC.

Kellert, S.R., J.H. Heerwagen, and M.L. Mador. 2008. Biophilic design: The theory, science, and practice of bringing buildings to life. Wiley, Hoboken, NJ. p. 385.

Kim, E. and R.H. Mattson. 2002. Stress recovery effects of viewing red-flowering geraniums. J. Ther. Hort. 13:4-12.

Knez, I. and S. Hygge. 2001. The circumplex structure of affect: A Swedish version. Scand. J. Psychol. 42:389-398.

Liu, M., E. Kim, and R.H. Mattson. 2003. Physiological and emotional influences of cut flower arrangements and lavender fragrance on university students. J. Ther. Hort. 14:18-27.

Lohr, V.I. and C.H. Pearson-Mims. 2000. Physical discomfort may be reduced in the presence of interior plants. HortTechnology 10:53-58.

Lohr, V.I., C.H. Pearson-Mims, and G.K. Goodwin. 1996. Interior plants may improve worker productivity and reduce stress in a windowless environment. J. Environ. Hort. 14:97-100.

Nordh, H., T. Hartig, C.M. Hagerhall, and G. Fry. 2009. Components of small urban parks that predict the possibility for restoration. Urban For. Urban Green. 8:225-235.

Normann, T., J.T. Sandvin, and H. Thommesen. 2004. A holistic approach to rehabilitation. Kommuneforlaget, Oslo, Norway.

Park, S.H., E. Kim, and R.H. Mattson. 2004. Horticultural therapy as an alternative medicine for pain management: Psychophysiological and psychological impacts of plant visual stimuli on pain tolerance and recovery. Appl. Psychophysiol. Biofeedback 29:291-292.

Park, S.H. and R.H. Mattson. 2008. Effects of flowering and foliage plants in hospital rooms on patients recovering from abdominal surgery. HortTechnology 18:563-568.

Park, S.H. and R.H. Mattson. 2009. Therapeutic influences of plants in hospital rooms on surgical recovery. HortScience 44:102-105.

Parsons, R., L.G. Tassinary, R.S. Ulrich, M.R. Hebl, and M. Grossman-Alexander. 1998. The view from the road: Implications for stress recovery and immunization. J. Environ. Psychol. 18:113-140.

Rubin, H.R., A.J. Owens, and G. Golden. 1998. An investigation to determine whether the built environment affects patients' medical outcomes. Center for Health Design, Martinez, CA.

Russell, J.A. 1979. Affective space is bipolar. J. Pers. Soc. Psychol. 37:345-356.

Russell, J.A. and A. Mehrabian. 1977. Evidence for a three-factor theory of emotions. J. Res. Pers. 11:273-294.

Tabachnick, B.G. and L.S. Fidell. 2007. Using multivariate statistics. 5th Ed. Pearson/Allyn and Bacon, Boston, MA.

Ulrich, R.S. 1983. Aesthetic and affective response to natural environment, p. 85-125. In: Altman, I. and J.F. Wohlwill (eds.). Human behavior and environment. Plenum Press, New York, NY.

Ulrich, R.S. 1984. View through a window may influence recovery from surgery. Science 224:420-421.

Ulrich, R.S. 1992. Effects of interior design on wellness: Theory and recent scientific research. J. Health Care Inter. Des. 3:97-109.

Ulrich, R.S., R.F. Simons, B.D. Losito, E. Fiorito, M.A. Miles, and M. Zelson. 1991. Stress recovery during exposure to natural and urban environments. J. Environ. Psychol. 11:201230.

Van den Berg, A.E. 2005. Health impact of healing environments: A review of evidence for benefits of nature, daylight, fresh air, and quiet in healthcare settings. The Architecture of Hospitals, Groeningen, The Netherlands.

Verderber, S. 1986. Dimensions of person-window transactions in the hospital environment. Environ. Behav. 18:450-466.

Ware, J.E., M. Kosinski, and S.D. Keller. 1996. A 12 -item short-form health survey: Construction of scales and preliminary tests of reliability and validity. Med. Care 34:220-233.

Ware, J.E., M. Kosinski, D.M. Turner-Bowker, and B. Gandek. 2005. How to score version 2 of the SF-12 Health Survey (with a supplement documenting version 1). Health Assessment Lab, Boston, MA. 